\title{
Preliminary Analysis of the Portuguese Version of the Child Anxiety Life Interference Scale
}

\author{
Análise Preliminar da Versão Portuguesa da Escala de Interferência \\ da Ansiedade na Criança
}

\author{
Teresa Marques*, Ana I. Pereira, Marta Pedro, Vanessa Russo, Ana R. Goes \& Luísa Barros \\ Universidade de Lisboa, Lisboa, Portugal
}

\begin{abstract}
Anxiety disorders are highly prevalent among school-aged children. These disorders become chronic in a substantial proportion of youths and cause significant interference with daily functioning. The purpose of the current investigation was to examine the psychometric properties of the Portuguese version of the Child Anxiety Life Interference Scale - Parent and Child versions (CALIS-P and CALIS-C). The sample consisted of 132 children between the ages of 7 and 12 with a main diagnosis of anxiety disorder and their parents. A factor analysis of the CALIS-P yielded three factors that agreed with the hypothesised subscales of At Home, Outside Home and Parent Life interference. For the CALIS-C, a factor analysis yielded two factors corresponding to Close Relationships and Performance interference that did not match the subscales of the original version. The internal consistency of the various CALIS subscales was good. Finally, evidence was found for both convergent and divergent validity. The CALIS scores were also significantly correlated with another measure of interference. The results provide initial support that the Portuguese version of the CALIS is a reliable and valid measure for the assessment of the impact of anxiety on child and family functioning.

Keywords: Childhood, anxiety disorders, life interference, assessment.
\end{abstract}

\begin{abstract}
Resumo
As perturbações de ansiedade são altamente prevalentes entre crianças em idade escolar. Estas perturbações tendem a seguir um curso crónico e interferem significativamente no funcionamento diário dos jovens. O objetivo principal deste estudo foi examinar as propriedades psicométricas da versão Portuguesa da Escala de Interferência da Ansiedade na Vida da Criança - versões para Pais e Crianças (CALIS-P e CALIS-C). Participaram 132 crianças, com idades entre os 7 e 12 anos, com diagnóstico principal de ansiedade, e seus respetivos pais. A análise fatorial da CALIS-P revelou três fatores que coincidem com as subescalas hipotetizadas: Interferência Em Casa, Fora de Casa e na Vida da Família. Para a CALIS-C, a análise fatorial revelou dois fatores que dizem respeito à Interferência nas Relações Próximas e no Desempenho, que não correspondem às subescalas da versão original. Os estudos psicométricos mostraram uma boa consistência interna para as várias subescalas da CALIS e boas qualidades na validade convergente e divergente. Foi observada ainda uma correlação significativa entre os resultados da CALIS e outra medida de interferência. Estes resultados sugerem que a versão portuguesa da CALIS é uma medida confiável e válida para a avaliação do impacto da ansiedade na criança e no funcionamento familiar.

Palavras-chave: Infância, perturbações de ansiedade, interferência, avaliação.
\end{abstract}

Epidemiological studies indicate that anxiety disorders are among the most common mental health problems in childhood and adolescence (Costello, Mustillo, Erkanli,

* Mailing address: Universidade de Lisboa, Faculdade de Psicologia, Alameda da Universidade, Lisboa, Portugal 1649-013. Phone: 00351 217943832; Fax: 00351 217933408. E-mail: teresamarques@campus.ul.pt Acknowledgements: This study received financial support from the Fundação para a Ciência e Tecnologia (PTDC/PSI-PCL/122007/2010). The authors thank Dr. Heidi Lyneham, Macquarie University, for the support provided in data analysis. The authors thank all schools, families and children, who collaborated and made possible this study.
Keeler, \& Angold, 2003)11.7\%-15.0\%. The onset of these disorders is typically in childhood and adolescence and they run a chronic course into adulthood (Albano, Chorpita, \& Barlow, 1998).

Given the high prevalence of these disorders, efforts to adequately capture their associated impact on daily activities is essential to increasing the understanding of the functional effects of childhood anxiety. Furthermore, interference evaluation is crucial for both the assessment and treatment of childhood anxiety disorders. On one hand, interference is a central aspect of the current conceptualisations of psychopathology and a key component for meeting diagnostic criteria (American Psychiatric 
Marques, T., Pereira, A. I., Pedro, M., Russo, V., Goes, A. R. \& Barros, L. (2015). Preliminary Analysis of the Portuguese Version of the Child Anxiety Life Interference Scale.

Association, 1994), which affects the decision of who receives treatment. On the other hand, interference is also an important tool to predict treatment needs and outcomes (Whiteside, 2009).

Additionally, the presence of interference in a child's and parents' life has been found to be a significant predictor of service use (Angold et al., 1998; Farmer, Burns, Angold, \& Costello, 1997; Teagle, 2002). This is particularly important because levels of service use have been found to be low despite the high rates of psychopathology in the community (Canino \& Shrout, 2004). Nevertheless, the primary focus in terms of the assessment and treatment of childhood psychopathology has been on symptoms. Far less attention has been paid to the impact of these symptoms on children's and families lives (Rapee, Bögels, van der Sluis, Craske, \& Ollendick, 2012).

The studies that have focused on anxiety impact have shown that anxiety disorders have a significant interference on children's and families lives. Childhood anxiety can interfere in multiple domains including academic, social and family functioning (Ezpeleta, Keeler, Erkanli, Costello, \& Angold, 2001; Strauss, Frame, \& Forehand, 1987). For example, Strauss et al. (1987) found that anxious children demonstrated a broad range of psychosocial difficulties when compared to non-anxious children including higher levels of depression and impairment in peer relations, self-esteem, attention, school performance and social behaviour as rated by their teachers, peers and by self-reports. Chansky and Kendall (1997) also found that both teachers and parents rated higher levels of social maladjustment in anxiety-disordered youth.

Demographic variables such as children's age and sex may also influence the interference anxiety has on child's life. Previous results on age and gender differences have been mixed. Regarding gender, some studies reported that girls display higher levels of interference (Langley et al., 2014; Lyneham et al., 2013) while others found no differences (Langley, Bergman, McCracken, \& Piacentini, 2004; Whiteside, 2009). Regarding age, one study found that older youth were more likely to experience impairment with social and school domains and were less likely to have impairments in functioning at home than were younger youth (Langley et al., 2014), but others found no differences between children and adolescents (Langley et al., 2004; Lyneham et al., 2013).

The main purpose of the current investigation was to examine the initial reliability of the Portuguese version of the Child Anxiety Life Interference Scale (CALIS) - Parent and Child versions in a sample of children diagnosed with anxiety disorders recruited from the community. The Child Anxiety Life Interference Scale was developed by Lyneham and collegues (2013) with the intent of measuring the interference that anxiety has on child's and parent's life. The CALIS consists of multiple scales designed to identify anxiety-related difficulties in children's school, social and home/family functioning from the child's and parent's perspective. When compared to the few other measures that exist to assess life interference and impairment, the CALIS has the advantage of being specific to the assessment of the interference related to child anxiety and of evaluating the direct impact that a child's anxiety has on his/her parents' life. The impact of child psychopathology on parents and family is recognised but has received little attention in the literature, despite the fact that it is impairment that typically brings consumers to services (Angold, Costello, Farmer, Burns, \& Erkanli, 1999) and the fact that children rarely self-present for help, which makes parents most often responsible for initiating help seeking (Lyneham \& Rapee, 2007).

The CALIS was shown to be a valid and reliable instrument. Data generated from one large-scale evaluation study indicates that the CALIS demonstrates good internal consistency, moderate-to-high test-retest reliability and significant inter-rater reliability (Lyneham et al., 2013). The study, which was conducted with a clinical sample of 622 children, showed evidence for both convergent and divergent validity: the measure correlated significantly with the report of internalizing symptoms, but not with externalizing symptoms. Furthermore, it was demonstrated that the CALIS is sensitive to treatment change (Lyneham et al., 2013).

In addition to the examination of the psychometric properties of the Portuguese version of the Child Anxiety Life Interference Scale, we explored the relationship between anxiety life interference and socio-demographics characteristics (age and gender) and previous children's mental health service use. Finally, we examined anxiety life interference in various anxiety diagnoses. To our knowledge, there are few studies that compared the impairment of various anxiety disorders. An example is the study of Beidel (1991), which showed that children with social phobia are more negatively impacted than youth with other anxiety disorders.

\section{Method}

\section{Participants}

The participants were 132 children with a principal diagnosis of anxiety disorder and their parents. The age of the children ranged from 7 to 12 year old children $(M$ $=9.68, S D=1.04)$. The sample had a balanced gender distribution, with $54 \%$ girls and $46 \%$ boys. The children were enrolled in $3^{\text {rd }}, 4^{\text {th }}, 5^{\text {th }}$ or $6^{\text {th }}$ grade in public, private and cooperative schools and lived mostly in semi-urban and urban areas in the vicinity of Lisbon, Portugal. Most of the parents were married (66\%) and in general the sample came from a variety of socio-economic status (SES estimated based on the parent's level of education and occupation), $33 \%$ low, $42 \%$ medium and $25 \%$ medium-high or high. Forty-two percent of the sample had previously resorted to professional help from the mental health services.

Regarding diagnosis, the most common anxiety disorders were generalised anxiety disorder and social phobia $(30 \%)$, followed by separation anxiety disorder $(23 \%)$ and 
specific phobia (17\%). Comorbidity was common in the sample with $75 \%$ having more than one anxiety diagnosis ( $28 \%$ had two, $31 \%$ had three and $16 \%$ had four or more).

\section{Measures}

The Screen for Child Anxiety Related Emotional Disorders-Revised - Parent/Child Versions (SCAREDR; Muris, Merckelbach, Schmidt, \& Mayer, 1999) is a self-report questionnaire containing 69 items that assess symptoms of various anxiety disorders in children: separation anxiety disorder, generalised anxiety disorder, panic disorder, social phobia, school phobia, specific phobia, obsessive-compulsive disorder and acute or posttraumatic stress disorder. Children and their parents rated how frequently the child experiences each symptom on a 3-point scale (0 - never or almost never, 1 - sometimes, or 2 - often). The scores for all types of anxiety are combined to yield a total score, which yielded a Cronbach's alpha of .94 for both parent and child versions.

The Anxiety Disorders Interview Schedule for DSM-IV - Child/Parent Version (ADIS-C/P; Silverman \& Albano, 1996). The ADIS-C/P is a semi structured interview for diagnosing anxiety disorders in youths. The interview initially probes respondents for the main criteria of a diagnosis, which when positively endorsed are then followed by a more detailed assessment of symptoms, level of fear, avoidance, and interference. The interference is rated on a 0 (not at all) to 8 (a great deal) scale. Although the ADIS-C/P primarily aims to establish anxiety disorder diagnoses, other disorders are also included. The ADIS$\mathrm{C} / \mathrm{P}$ has acceptable to excellent test-retest reliability (Silverman, Saavedra, \& Pina, 2001) and inter-rater agreement (Lyneham, Abbott, \& Rapee, 2007). In the current study, we interviewed parents and children together following the procedure of Khanna and Kendall (2010). Only the sections assessing anxiety disorders, mood disorders and externalising disorders were administered.

The Child Anxiety Life Interference Scale (CALIS$\mathrm{C}$ and CALIS-P; Lyneham et al., 2013). The CALIS-C (9-item) and CALIS-P (16-item) provides two parallel measures (one reported by the child and the other by his/ her parents) that assess the extent to which the child's anxiety impacts on the child's school, social and home/ family functioning. The CALIS-P also provide an additional set of items that evaluate the interference that child's anxiety has on the parents' life. The items are divided into three subscales: Outside Home Interference and At Home Interference (both for child report and reports about child by parent) and Parent Life Interference (for parent reports only). The scores for all items relevant to interference in the child's life are combined to yield a total score - Child Life Interference (child and parent report) and for the parent report all items are combined to yield a total score - Total Score. Each item is rated on a 5 point Likert scale: (0) not at all, (1) only a little, (2) sometimes, (3) quite a lot and (4) a great deal. The CALIS demonstrates good internal consistency ( $\alpha$ 's between .70 and .90), moderate- to-high test-retest reliability ( $r$ 's between .66 and .91) and significant inter-rater reliability ( $r$ 's between .37 and .50 ; Lyneham et al., 2013).

The Strengths and Difficulties Questionnaire - Parent Version (SDQ; R. Goodman, 1997) is a brief screening questionnaire with 25 items that aim to assess the psychological adjustment of children and adolescents. The 25 items are divided between five scales: emotional symptoms, conduct problems, hyperactivity/inattention, peer problems and pro-social behaviour. The extended version of the SDQ also has an impact supplement but it was not used in this study. Parents were asked to rate the degree to which various items correspond to the behaviour of their children in the last six months using a 3-point scale (1 - not true, 2 - somewhat true, or 3 - certainly true). For the purpose of this study, the internalising and externalising composites recommended by A. Goodman, Lamping and Ploubidis (2010) were used for the analyses. Internal consistency in the current sample was $\alpha=.55$ for the internalising scale and $\alpha=.76$ for the externalising scale.

\section{Procedure}

The data was collected in the context of a larger study (CATCh - Children Anxiety Treatment and Change). The study was approved by the General Administration for Innovation and Curriculum Development, the Faculty of Psychology Ethics Committee of the University of Lisbon and organised in collaboration with the school boards and teachers of the schools involved. Children were recruited from Portuguese public and private schools. The recruitment was conducted in two phases (see Figure 1).

After receiving an informed consent form, $74 \%$ of the parents allowed their children to participate in the first phase of the study, which was a universal screening process to identify children with high levels of anxiety symptoms. All of the children who were authorised to participate in the study answered to the child's version of SCARED-R during a class and their mothers answered the parent's version that was sent home. All of the children who scored above the $95^{\text {th }}$ percentile for the total scale or the subscales of generalised anxiety disorder, separation anxiety disorder or social phobia on either the parent's or child's version were invited to participate in the second phase of the study.

The majority of parents and children agreed to participate in the second phase of the study where the ADIS - C/P interviews were administered. Following assessment, the children and parents of those who met the criteria for a principal diagnosis of an anxiety disorder completed the CALIS child and parent versions. The remaining questionnaire to be completed by the parents (SDQ) was sent home and returned to the researcher by the teacher.

\section{Statistical Analysis}

As noted previously, the primary purpose of this study was to explore the psychometric properties of the Portuguese version of the Child Anxiety Life Interference 
Marques, T., Pereira, A. I., Pedro, M., Russo, V., Goes, A. R. \& Barros, L. (2015). Preliminary Analysis of the Portuguese Version of the Child Anxiety Life Interference Scale.

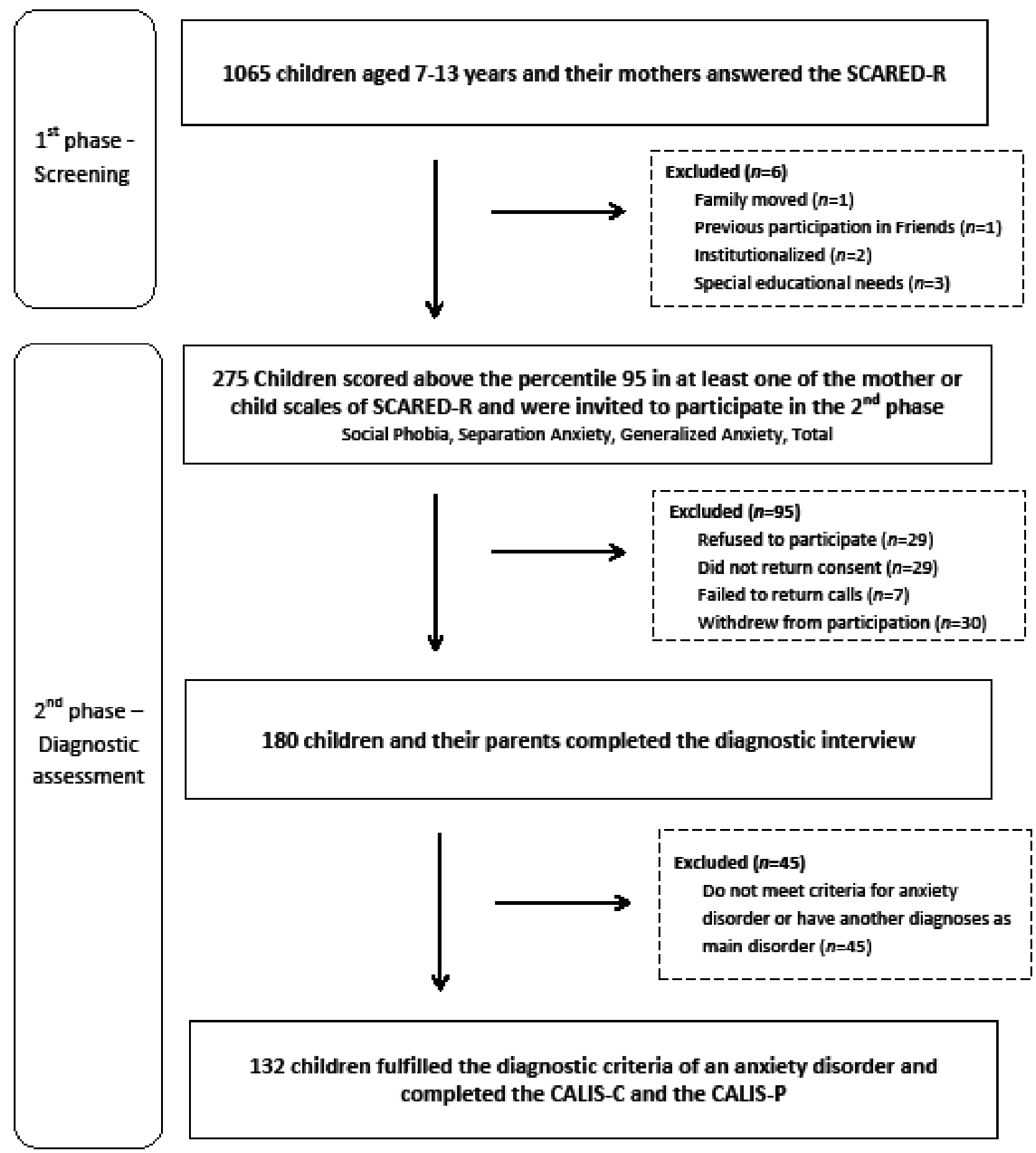

Figure 1. Flow diagram of participants' progress through the phases of the study.

Scale (CALIS) - Parent and Child's versions. To meet this objective, we carried out a principal-components factor analysis using varimax rotation. Only the factors that had eigenvalues greater than one were retained for interpretation. Furthermore, we computed descriptive statistics (means, standard deviations), reliability coefficients and correlations between CALIS-C and CALIS-P and other measures of anxiety severity, psychological adjustment and interference. Finally, to explore the relationships between anxiety life interference and socio-demographics characteristics, previous mental health service utilisation and specific anxiety diagnoses, a series of analyses were conducted using Kruskal Wallis and Mann-Whitney tests.

\section{Results}

Factor Analysis and Internal Consistency

Parent Report. On the parent's report, the exploratory factor analysis yielded three factors with eigenvalues $>$ 1.0 (i.e., $6.1,1.6$ and 1.2), which accounted for $55 \%$ of 
the variance. After a varimax rotation, the items loading together indicated factors representing interference in the Parent Life, Outside Home and At Home factors, which was similar to the original scale. The items loaded clearly on their designated factor with factor loadings greater or equal to .40 (Table 1). However, the item "Child Daily Activities" loaded both highly on the Outside Home factor (factor loading of .41) and on the At Home factor (factor loading of .39). Given that this item belonged to the At Home factor on the original scale, we chose to allocate it in this factor to comply with the original scale.

The inter-subscales correlation between the outside and inside home factors was .58 $(p<.001)$. The correlation between the inside home and parent life factors was .53 $(p<.001)$ and the correlation between the outside home and parent life factors was $.51(p<.001)$. The Cronbach's alphas were .71 for the At Home Interference, .75 for the Outside Home Interference and .82 for the Child Life Interference. The alpha for Parent Life Interference was .85. Finally, The Cronbach's alphas for the parent report total scale was .89. All of the inter-item correlations were lower than .70, which indicates that the items were not redundant.

Child Report. For the child's report, this analysis yielded two factors with eigenvalues $>1.0$ (i.e., 2.7 and 1.6) which accounted for $49 \%$ of the variance. After a varimax rotation, each of the items had factor loadings greater than .40 , with the exception of the item "child's distress" that presented a factor loading of .39 (Table 1). The item composition of these factors indicates a different structure from the original scale. The inspection of the item contents suggests that Factor 1 refers to interference in Close Relationships and that Factor 2 consisted of the six items related to interference in Performance. The inter-subscales correlation between the Close Relationships and the Performance factors was .31 $(p<.001)$. The Cronbach's alphas were .72 for the Interference in Close Relationships, .68 for the Performance Interference and .71 for the Child Life Interference. All of the inter-item correlations were lower than .70, which indicates that the items were not redundant.

Table 1

Factor Loadings for the CALIS

Child Report Mother Report

Item/Factor

Factor 1

Factor 2

Factor 1

Factor 2 Factor 3

Child Life

Child Sibling Relationship

.04

Child Parent Relationship

.09

Child with Friends Outside of School

.11

Child Daily Activities

.71

Child Distress

Child Interacting with School Peers

Child Sport Participation

.60

Child Enjoyable Activities

.58

Child Schoolwork

.67

.88
.79
.68
-.01
.31
-.01
.18
.18
.13

$$
\begin{aligned}
& .15 \\
& .14 \\
& .14 \\
& .29 \\
& .16 \\
& .10 \\
& .22 \\
& .33
\end{aligned}
$$$$
.14
$$$$
.16
$$$$
.22
$$$$
.15
$$

14

.25

.32

.39

.41

.82

.30

.75

$-.01$

.78

.13

Parent Life

Parent Relationship with Friends
Parent Relationship Extended Family
Parent Relationship with Partner
Parent Out without Child
Parent Going Out with Child
Parent Stress Level
Parent Career


Marques, T., Pereira, A. I., Pedro, M., Russo, V., Goes, A. R. \& Barros, L. (2015). Preliminary Analysis of the Portuguese Version of the Child Anxiety Life Interference Scale.

\section{Descriptive Statistics}

The CALIS-P items that were most frequently reported as causing significant interference (rated as 3 , "quite a lot" or 4, "a great deal") were as follows: Child Schoolwork (24\%), Child Distress (17\%) and Parent Stress Level $(16 \%)$. The CALIS-C items that were most frequently endorsed were as follows: Child Distress (24\%) and Child Daily Activities (11\%).

The means and standard deviations for each subscale are presented in Table 2. When comparing the child and parent report on the comparable subscale (Child life interference), we found a significant difference $(Z=-3.08, p=$ .002 ), with parents reporting significantly higher levels of interference in the child's life.

Table 2

Descriptive Statistics for the Scale Scores on the Child Anxiety Life Interference Scale

\begin{tabular}{lccccc}
\hline & Male & Female & $7-9$ yrs & $10-12$ yrs & Total \\
\hline Parent Report & $n=61$ & $n=71$ & $n=54$ & $n=78$ & $n=132$ \\
$\quad$ Total Score & $12.82(9.15)$ & $14.03(9.97)$ & $12.83(10.57)$ & $13.91(8.87)$ & $13.47(9.58)$ \\
Child Life & $7.87(5.16)$ & $8.87(6.29)$ & $8.04(5.98)$ & $8.67(5.69)$ & $8.41(5.80)$ \\
Outside Home & $4.02(3.36)$ & $4.65(3.94)$ & $4.19(3.90)$ & $4.47(3.54)$ & $4.36(3.68)$ \\
At Home & $3.85(2.52)$ & $4.23(3.02)$ & $3.85(2.79)$ & $4.19(2.81)$ & $4.05(2.80)$ \\
Parent Life & $4.95(4.93)$ & $5.15(4.78)$ & $4.80(5.33)$ & $5.24(4.48)$ & $5.06(4.83)$ \\
Child Report & $n=61$ & $n=71$ & $n=54$ & $n=78$ & $n=132$ \\
Child Life & $5.98(4.12)$ & $7.11(5.72)$ & $7.00(5.37)$ & $6.31(4.84)$ & $6.59(5.06)$ \\
Close Relationships & $2.02(2.36)$ & $1.99(2.80)$ & $2.59(2.99)$ & $1.59(2.20)$ & $2.00(2.59)$ \\
Performance & $3.97(2.77)$ & $5.13(4.33)$ & $4.41(3.45)$ & $4.72(3.93)$ & $4.59(3.73)$ \\
\hline
\end{tabular}

\section{Convergent, Divergent and Concurrent Validity}

Correlational analyses between the CALIS-C and CALIS-P and other measures of anxiety severity (SCARED$\mathrm{R})$ and psychological adjustment (SDQ) were conducted to examine the convergent and divergent validity of the subscales. The concurrent validity of the CALIS-C and CALIS-P was examined through correlations with the interference scale from the ADIS-C/P. For each correlation reported, only the correspondent self-report versions were analysed (e.g., the child self-reported interference with the child self-reported anxiety severity and the parent-reported interference with the parent-reported anxiety severity). These are reported together with the correlation coefficients and significance levels in Table 3.

Parent Report. Weak to moderate positive significant correlations were found between the CALIS-P Subscales and the SDQ Internalising Composite and between the SCARED-R Total Score and the ADIS-C/P Interference Scale. The CALIS-P Subscales were not correlated significantly with the SDQ Externalising Composite except for the Outside Home Interference subscale, which presented a weak positive correlation.

Child Report. Similar to the parent report, the CALIS-C Subscales presented weak to moderate positive significant correlations with the SCARED-R Total Score and the ADIS-C/P Interference Scale, with the exception of the
Close Relationships Subscale that did not correlated significantly with the SCARED-R Total Score.

\section{Differences Regarding Socio-Demographic} Characteristics, Mental Health Service Utilisation and Anxiety Diagnoses

We also examined the relationships between anxiety life interference and socio-demographics characteristics, previous mental health service utilisation and specific anxiety diagnoses. These analyses were made based on the Child life interference (total score) from the child report and the Child life interference and Parent Life interference from the parent report to enable comparison across reporters.

First, we examined whether there were significant differences regarding age and gender. No significant differences were found regarding age (Child: Child Life $-U$ $=1899.50, p=.34$; Parent: Child Life $-U=1924.00, p=$ .40 , Parent Life $-U=1846.50, p=.23$ ) or gender (Child: Child Life $-U=2056.50, p=.82$; Parent: Child Life $-U$ $=1720.50, p=.07$, Parent Life $-U=1737.50, p=.09$ ) for either report.

In addition, significant differences were found regarding the Child Life interference reported by the parents when comparing parents who indicated that they had sought professional help for an emotional or behavioural 
Table 3

Correlation Analyses between the CALIS-C and CALIS-P and Other Measures of Anxiety Symptoms (SCARED-R), Psychological Adjustment (SDQ) and Anxiety Interference (ADIS-C/P)

\begin{tabular}{lcccc}
\hline & SCARED-R & SDQ - INT & SDQ - EXT & ADIS Anx Interference \\
\hline Parent Report & $n=129$ & $n=114$ & $n=114$ & $n=132$ \\
Total Score & $.25^{* *}$ & $.44^{* *}$ & .14 & $.49^{* *}$ \\
Child Life & $.25^{* *}$ & $.43^{* *}$ & .15 & $.45^{* *}$ \\
Outside Home & $.19^{*}$ & $.40^{* *}$ & $.19^{*}$ & $.34^{* *}$ \\
At Home & $.26^{* *}$ & $.35^{* *}$ & .05 & $.47^{* *}$ \\
Parent Life & $.18^{*}$ & $.39^{* *}$ & .07 & $.43^{* *}$ \\
Child Report & $n=132$ & & & $n=132$ \\
Child Life & $.23^{* *}$ & & & $.48^{* *}$ \\
Close Relationships & .09 & & & $.31^{* *}$ \\
Performance & $.20^{*}$ & & $.42^{* *}$ \\
\hline
\end{tabular}

Note. Coefficients correlate same reporters for each measure. SCARED-R = Screen for Child Anxiety Related Emotional DisordersRevised; SDQ-INT = Strengths and Difficulties Questionnaire Internalizing Composite; SDQ-EXT $=$ Strengths and Difficulties Questionnaire Externalizing Composite.

$* p<.05 ; * *<.01$.

difficulty experienced by their child and the ones that did $\operatorname{not}(U=1356.00, p<.001)$. Parents who had previously sought help for their children reported higher levels of child life interference. These differences were not found for the Parent Life Interference subscale $(U=1728.50, p$ $=.06)$ or the child report $(U=1859, p=.21)$.

Finally, when comparing between anxiety diagnoses, differences were found for the Child Life Interference subscales for both the child, $H(3)=9.73, p=.02$, and parent reports, $H(3)=7.98, p=.046$. Post hoc tests for the child report showed that children with a principal diagnosis of generalised anxiety reported higher levels of interference than children with a principal diagnosis of social $(U=573.00, p=.04)$ or a specific phobia $(U$ $=246.00, p=.002)$. Post hoc tests for the parent report showed that parents of children with a principal diagnosis of generalised anxiety reported higher levels of interference than parents of children with a principal diagnosis of a specific phobia $(U=307.00, p=.002)$. No significant differences were found regarding the Parent Life subscale, $H(3)=5.28, p=.15$.

\section{Discussion}

The current study examined the psychometric properties of the Portuguese version of the Child Anxiety Life Interference Scale - Parent and Child versions. Our results suggest that the Portuguese version of the CALIS-P has similar properties to the original version. At a structural level, the CALIS-P has the same format with an internal consistency that is comparable to that of the original and displays a good internal consistency on both the total score and the subscales.

Regarding the child report, although the CALIS-C presented a two-factor structure as the original version, the item loadings were quite different. One possible explanation for the different splitting that we found is related to cultural specificities. In this two-factor splitting, one domain seems to be related specifically to the child's close relationships (child-sibling relationship, child-parent relationship and child with friends outside of school); the other domain seems more heterogeneous, but most of the items have to do with performance in various activities. However, the item "child interacting with school peers" loads with performance and not with relationships. The higher loading of this item in the performance dimension can be explained by the fact that this item has to do with interactions in the school domain with colleagues/ peers. This item is possibly more related to interference in performance issues (social performance) than interference with close relationships. Therefore, we propose this performance/relationships split by taking into account that anxiety interference can vary depending on the cultural setting and how the children themselves view the role of school in their friendships in particular. Finally, it is worth emphasising that the total score remains the same because none of the items were redundant. The total score displays a good internal consistency, comparable with the original version. The new subscales present a good internal consistency as well. 
Marques, T., Pereira, A. I., Pedro, M., Russo, V., Goes, A. R. \& Barros, L. (2015). Preliminary Analysis of the Portuguese Version of the Child Anxiety Life Interference Scale.

The convergent validity of both versions of the CALIS was supported by significant correlations with related measures, while the divergent validity of the measure was corroborated by the lack of correlation with measures assessing presumably more unrelated constructs. Specifically, the measure shows significant and weak-to-moderate correlations with the report of internalising symptomatology (SCARED-R and SDQ - internalising symptoms subscale) but not with the externalising symptomatology (SDQ - externalising symptoms subscale). The exceptions were the Close Relationships subscale (child report), which did not correlate significantly with the SCARED-R total score and the Outside Home subscale (parent report), which presented a correlation of low magnitude with the SDQ externalising symptoms subscale. These weak-to-moderate associations could be the result of the characteristics of our sample. Our sample was recruited from the community and therefore differ considerably from clinic-referred children and adolescents (Southam-Gerow, 2003; Stirman, DeRubeis, Crits-Christoph, \& Brody, 2003). In particular, because these children did not seek treatment from specialist settings they may be less impaired despite being diagnosed with an anxiety disorder (Angold et al., 1999).

CALIS scores were also significantly correlated with an alternative validated measure of interference (ADIS$\mathrm{C} / \mathrm{P}$ Interference Scale). These moderated associations are consistent with what previous studies have found (Lyneham et al., 2013; Whiteside, 2009). Moreover, Lyneham et al. (2013) argued that the strength of these correlations provide a compelling argument for the need for an anxietyspecific life interference measure.

Globally, these results provide initial evidence that the Portuguese version of the CALIS is a reliable and valid measure for the assessment of the impact of anxiety on child and adolescent functioning.

The results regarding the individual analysis of items revealed that parents and children have different perspectives on what areas are most affected by anxiety in children: parents report child schoolwork to be the more impaired area and children report higher interference in child daily activities. Furthermore, parents reported significantly higher levels of child interference. Discrepancies between child and parent reports are not uncommon and prior research has shown that informant reports can vary according to where they observe child behaviour and where the child express the behaviours being assessed (e.g., Achenbach, McConaughy, \& Howell, 1987). Thus, these discrepancies can be an expression of different perspectives and may suggest that parents are more attentive to the interference of these disorders.

No differences in CALIS scores were found based on age or gender. As mentioned before, previous results on age and gender differences have been mixed with some studies finding differences regarding age and gender and others finding no differences. More research is required on this topic, and an effort should be made to perform such studies under optimal conditions. For example, the lack of differences regarding age on this study may have been related to the restricted age range of our sample.

In addition, the findings show that parents who had previously sought professional help for an emotional or behavioural difficulty experienced by their child reported higher levels of child interference than did the parents who had not previously sought such help. This result is not surprising because parents are most often responsible for initiating help seeking and child impairment has been found to increase parental problem recognition (Costello et al., 1996; Teagle, 2002), both of these variables are responsible for a significant increase in the likelihood of service use (Angold et al., 1998; Farmer et al., 1997; Teagle, 2002).

Moreover, the results also show significant differences both in the child and parent reports regarding impairment among various anxiety disorders. For the child interference scale, both parents and children reported higher levels of impairment for the children with a principal diagnosis of generalised anxiety than for the children with a principal diagnosis of a specific phobia. Additionally, on the child's report, children with generalised anxiety also display significantly higher levels of impairment that did children with social phobia as their principal diagnosis.

\section{Limitations and Future Directions}

There are a number of limitations that need to be considered when interpreting the results of this study. First, this is a cross-sectional study. Future studies should establish retest reliability and the predictive validity of the CALIS via longitudinal designs. Second, the fact that we used a sample recruited from the community does not allow for the generalisation of the results to clinicreferred children and adolescents diagnosed with anxiety disorders. Our results require replication, for example through confirmatory factor analysis, in larger and more broadly representative samples. Additional analysis of the specificity and treatment sensitivity of these measures is also recommended.

Despite these limitations, the present results provide initial support that the Portuguese version of the CALIS is a reliable and valid measure. This is of great relevance given the importance of assessing interference in daily functioning and measuring functional outcomes in both research and clinical practice. In the clinical practice, assessing interference alongside with symptom presence will improve the ability of clinicians to correctly identify children with an anxiety disorder and to determine treatment goals. As a research tool, it may be useful for studying the relations between anxiety symptoms and interference in daily functioning.

\section{References}

Achenbach, T. M., McConaughy, S. H., \& Howell, C. T. (1987). Child / adolescent behavioral and emotional problems : Implications of cross-informant correlations for situational specificity. Psychology Bulletin, 101, 213-232. doi:10.1037//00332909.101.2.213 
Albano, A. M., Chorpita, B. F., \& Barlow, D. H. (1998). Childhood anxiety disorders. In E. J. Mash \& R. A. Barkley (Eds.), Child psychopathology (pp. 279-329). New York: Guilford Press.

American Psychiatric Association. (1994). Diagnostic and statistical manual of mental disorders ( $4^{\text {th }}$ ed.). Washington, DC: Author.

Angold, A., Costello, E. J., Farmer, E. M., Burns, B. J., \& Erkanli, A. (1999). Impaired but undiagnosed. Journal of the American Academy of Child and Adolescent Psychiatry, 38(2), 129-137. doi:10.1097/00004583-199902000-00011

Angold, A., Messer, S. C., Stangl, D., Farmer, E. M., Costello, E. J., \& Burns, B. J. (1998). Perceived parental burden and service use for child and adolescent psychiatric disorders. American Journal of Public Health, 88, 75-80. doi:10.2105/ AJPH.88.1.75

Beidel, D. C. (1991). Social phobia and overanxious disorder in school-age children. Journal of the American Academy of Child and Adolescent Psychiatry, 30, 545-552. doi:10.1097/00004583-199107000-00003

Canino, G., \& Shrout, P. (2004). The DSM-IV rates of child and adolescent disorders in Puerto Rico: Prevalence, correlates, service use, and the effects of impairment. Archives of General Psychiatry, 61, 85-93. doi:10.1001/archpsyc.61.1.85

Chansky, T., \& Kendall, P. (1997). Social expectancies and selfperceptions in anxiety-disordered children. Journal of Anxiety Disorders, 11, 347-363. doi:10.1016/S0887-6185(97)00015-7

Costello, E. J., Angold, A., Burns, B. J., Erkanli, A., Stangl, D., \& Tweed, D. L. (1996). The Great Smoky Mountains Study of youth: Functional impairment and severe emotional disturbance. Archives of General Psychiatry, 53, 1137-1143. doi:10.1001/archpsyc.1996.01830120077013

Costello, E. J., Mustillo, S., Erkanli, A., Keeler, G., \& Angold, A. (2003). Prevalence and development of psychiatric disorders in childhood and adolescence. Archives of General Psychiatry, 60, 837-844. doi:10.1001/archpsyc.60.8.837

Ezpeleta, L., Keeler, G., Erkanli, A., Costello, E. J., \& Angold, A. (2001). Epidemiology of psychiatric disability in childhood and adolescence. Journal of Child Psychology and Psychiatry, and Allied Disciplines, 42, 901-914. doi:10.1111/14697610.00786

Farmer, E. M. Z., Burns, B. J., Angold, A., \& Costello, E. J. (1997). Impact of children's mental health problems on families: Relationships with service use. Journal of Emotional and Behavioral Disorders, 5, 230-238. doi:10.1177/106342669700500406

Goodman, A., Lamping, D. L., \& Ploubidis, G. B. (2010). When to use broader internalising and externalising subscales instead of the hypothesised five subscales on the Strengths and Difficulties Questionnaire (SDQ): Data from British parents, teachers and children. Journal of Abnormal Child Psychology, 38, 1179-1191. doi:10.1007/s10802-010-9434-x

Goodman, R. (1997). The Strengths and Difficulties Questionnaire: A research note. Journal of Child Psychology and Psychiatry, and Allied Disciplines, 38, 581-586. doi:10.1111/j.1469-7610.1997.tb01545.x

Khanna, M. S., \& Kendall, P. C. (2010). Computer-assisted cognitive behavioral therapy for child anxiety: Results of a randomized clinical trial. Journal of Consulting and Clinical Psychology, 78, 737-745. doi:10.1037/a0019739

Langley, A. K., Bergman, R. L., McCracken, J., \& Piacentini, J. C. (2004). Impairment in childhood anxiety disorders: Preliminary examination of the child anxiety impact scale-parent version. Journal of Child and Adolescent Psychopharmacology, 14, 105-114. doi:10.1089/104454604773840544
Langley, A. K., Falk, A., Peris, T., Wiley, J. F., Kendall, P. C., Ginsburg, G., ...Piacentini, J. (2014). The Child Anxiety Impact Scale: Examining parent- and child-reported impairment in child anxiety disorders. Journal of Clinical Child and Adolescent Psychology, 43(4), 579-591. doi:10.1080/1 5374416.2013.817311

Lyneham, H. J., Abbott, M. J., \& Rapee, R. M. (2007). Interrater reliability of the anxiety disorders interview schedule for DSM-IV: Child and parent version. Journal of American Academy of Child and Adolescent Psychiatry, 46, 731-736. doi:10.1097/chi.0b013e3180465a09

Lyneham, H. J., \& Rapee, R. M. (2007). Childhood anxiety in rural and urban areas: Presentation, impact and help seeking. Australian Journal of Psychology, 59(2), 108-118. doi:10.1080/00049530701317082

Lyneham, H. J., Sburlati, E. S., Abbott, M. J., Rapee, R. M., Hudson, J. L., Tolin, D. F., \& Carlson, S. E. (2013). Psychometric properties of the Child Anxiety Life Interference Scale (CALIS). Journal of Anxiety Disorders, 27, 711-719. doi:10.1016/j.janxdis.2013.09.008

Muris, P., Merckelbach, H., Schmidt, H., \& Mayer, B. (1999). The revised version of the Screen for Child Anxiety Related Emotional Disorders (SCARED-R): Factor structure in normal children. Personality and Individual Differences, 26, 99-112. doi:10.1016/S0191-8869(98)00130-5

Rapee, R. M., Bögels, S. M., van der Sluis, C. M., Craske, M. G., \& Ollendick, T. (2012). Annual research review: Conceptualising functional impairment in children and adolescents. Journal of Child Psychology and Psychiatry, and Allied Disciplines, 53, 454-468. doi:10.1111/j.1469-7610.2011.02479.x

Silverman, W. K., \& Albano, A. M. (1996). The Anxiety Disorders Interview Schedule for DSM-IV - Child and Parent Versions. London: Oxford University Press.

Silverman, W. K., Saavedra, L. M., \& Pina, A. A. (2001). Test-retest reliability of anxiety symptoms and diagnoses with the Anxiety Disorders Interview Schedule for DSMIV: Child and parent versions. Journal of the American Academy of Child and Adolescent Psychiatry, 40, 937-944. doi:10.1097/00004583-200108000-00016

Southam-Gerow, M. (2003). Youth with anxiety disorders in research and service clinics: Examining client differences and similarities. Journal of Clinical Child and Adolescent Psychology, 32, 375-385. doi:10.1207/S15374424JCCP3203 06

Stirman, S. W., DeRubeis, R. J., Crits-Christoph, P., \& Brody, P. E. (2003). Are samples in randomized controlled trials of psychotherapy representative of community outpatients? A new methodology and initial findings. Journal of Consulting and Clinical Psychology, 71, 963-972. doi:10.1037/0022006X.71.6.963

Strauss, C., Frame, C., \& Forehand, R. (1987). Psychosocial impairment associated with anxiety in children. Journal of Clinical Child Psychology, 16, 235-239. doi:10.1207/ s15374424jecp1603 8

Teagle, S. E. (2002). Parental problem recognition and child mental health service use. Mental Health Services Research, 4, 257-266. doi:10.1023/A:1020981019342

Whiteside, S. P. (2009). Adapting the Sheehan Disability Scale to assess child and parent impairment related to childhood anxiety disorders. Journal of Clinical Child and Adolescent Psychology, 38, 721-730. doi:10.1080/15374410903103551 